\title{
The challenges of pain management in primary care: a pan-European survey
}

This article was published in the following Dove Press journal: Journal of Pain Research

21 May 2013

Number of times this article has been viewed

Martin Johnson'

Beverly Collett ${ }^{2}$

José M Castro-Lopes ${ }^{3}$

On behalf of OPENMinds

Primary Care

'Community Pain Medicine, Cardiff University, Cardiff, UK; ${ }^{2}$ Pain Management Service, University Hospitals of Leicester NHS Trust, Leicester, UK; ${ }^{3}$ Department of Experimental Biology, Faculty of Medicine of the University of Porto, Porto, Portugal

Video abstract

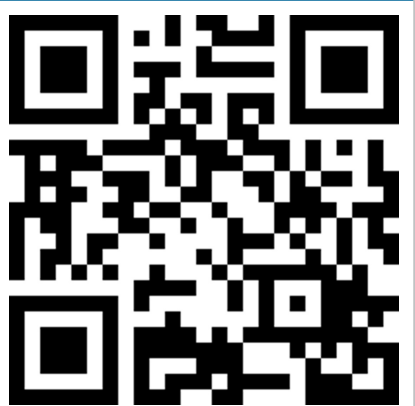

Point your SmartPhone at the code above. If you have a QR code reader the video abstract will appear. Or use: http://dvpr.es//3ne854
Correspondence: Martin Johnson

Community Pain Medicine,

Cardiff University, Cardiff, UK

Tel +44 (0) 7775506109

Email martin.johnson58@me.com
Background: The OPENMinds Primary Care group is a group of European primary care physicians (PCPs) with an interest in pain management, formed to improve the understanding and management of chronic pain in primary care.

Objective: A survey was conducted to assess the challenges of chronic nonmalignant pain (CNMP) management in primary care in Europe, focusing particularly on pain assessment, opioid therapy, and educational needs.

Methods: A questionnaire was developed for online use by PCPs in 13 European countries (Belgium, Denmark, France, Germany, Ireland, Italy, the Netherlands, Norway, Poland, Portugal, Spain, Sweden, and the UK).

Results: A total of 1309 PCPs completed the questionnaire, approximately 100 from each country. Most PCPs (84\%) perceived CNMP to be one of the most challenging conditions to treat, yet a low priority within healthcare systems. Only $48 \%$ of PCPs used pain assessment tools, and $81 \%$ considered chronic pain and its impact on quality of life to be underassessed in primary care. PCPs were less confident about prescribing strong opioids for CNMP than for use in cancer pain. Most PCPs (84\%) considered their initial training on CNMP was not comprehensive, with $89 \%$ recognizing a need for more education on the topic.

Conclusion: These findings reveal that PCPs in Europe find CNMP a challenge to treat. Areas to address with training include underuse of pain assessment tools and lack of confidence in use of opioid therapy. Guidelines on CNMP management in primary care would be welcomed. The insights gained should provide the basis for future initiatives to support primary care management of chronic pain.

Keywords: primary care physicians, chronic pain, opioid analgesics, Europe

\section{Introduction}

It is estimated that $70 \%$ of patients with chronic pain are managed in primary care. ${ }^{1}$ Chronic pain is a key reason for consulting primary care physicians (PCPs), accounting for $22 \%$ of presenting conditions, ${ }^{2}$ with over a third of adult appointments with a PCP involving a patient in chronic pain. ${ }^{3}$ Furthermore, patients with chronic pain consult their PCPs five times more frequently than patients without such pain. ${ }^{4}$ With such extensive and regular exposure to the needs of patients with chronic pain, it might be expected that PCPs would be highly confident and proficient in its management. However, at least $40 \%$ of patients with chronic pain treated in a routine practice setting do not achieve adequate pain relief. ${ }^{5}$ This suggests that chronic pain management presents a challenge to many physicians. ${ }^{6}$

Surveys of PCPs conducted in the USA report considerable frustration and dissatisfaction with the management of chronic pain. ${ }^{3,7}$ These and other surveys conducted 
in North America identified challenges, including a lack of confidence in chronic pain management, concerns about the use of opioid analgesia, and dissatisfaction with training. ${ }^{8,9}$ Similar challenges may face European PCPs.

With this in mind, the pan-European Opioids and Pain European Network of Minds (OPENMinds) Primary Care group (OMPC) was formed, to act synergistically with the already established OPENMinds group of leading European experts who specialize in the research and management of pain. The OMPC aims to explore initiatives that enhance pain management in primary care in Europe. The first initiative of the OMPC was a survey of PCPs to assess the challenges of chronic nonmalignant pain (CNMP) management in primary care in Europe, focusing particularly on pain assessment, opioid therapy, and educational needs. The findings should form an evidence base for future initiatives.

\section{Materials and methods Questionnaire development}

The OMPC group met in November 2010 and identified CNMP and opioid analgesia as particular problems encountered by PCPs. The OMPC Steering Committee developed a questionnaire on chronic pain (pain present for at least 3 months, several days per month, and present in the last month), as defined by the International Association for the Study of Pain (IASP). ${ }^{10}$ The questionnaire (see Supplementary material) was translated into European languages that were appropriate for the target countries. Back-translation was used to check for the validity of the terminology used.

\section{Respondents}

The research was conducted online to reach a large number of respondents from different countries in a timely and efficient manner. An online panel of more than 500,000 physicians across Europe was used. From this panel, a sample of approximately 100 PCPs was taken from each of 13 European countries (Belgium, Denmark, France, Germany, Ireland, Italy, the Netherlands, Norway, Poland, Portugal, Spain, Sweden, and the UK). The samples were selected to be nationally representative in terms of sex, age, and regional distribution. All respondents were PCPs (3-45 years of experience) spending at least 20 hours each week in direct patient care. Respondents received compensation (within accepted guidelines) for their participation. Fieldwork was undertaken in July 2011.

\section{Statistical methods}

Responses to each question were collated and analyzed for the total group and for subgroups defined by sex, years in practice, practice size, and country. Responses within subgroups were compared using one way analysis of variance (ANOVA), followed by the Bonferroni $t$-test for multiple comparisons or by the Student's $t$-test when comparing only two groups; a $P$-value $<0.05$ was considered statistically significant.

\section{Results}

A total of 1309 PCPs completed the questionnaire (Table 1).

\section{Does management of CNMP present a challenge to PCPs?}

Patients with CNMP were seen as challenging to manage by $88 \%$ of PCPs, though this view was less likely among

Table I Demographic characteristics of PCPs participating in the survey

\begin{tabular}{|c|c|c|c|c|c|c|c|c|c|}
\hline & Total & Males & $\begin{array}{l}\text { Mean } \\
\text { years in } \\
\text { practice }\end{array}$ & $\begin{array}{l}\text { Mean hours per } \\
\text { week in direct } \\
\text { patient care }\end{array}$ & $\begin{array}{l}\text { Mean no } \\
\text { patients seen } \\
\text { per month }\end{array}$ & $\begin{array}{l}\text { Single PCP } \\
\text { practice }\end{array}$ & $\begin{array}{l}\text { 2-5 PCPs } \\
\text { in practice }\end{array}$ & $\begin{array}{l}\geq 6 \mathrm{PCPs} \\
\text { in practice }\end{array}$ & $\begin{array}{l}\text { Part of } \\
\text { large } \\
\text { MDT }\end{array}$ \\
\hline Total & 1309 & 949 (72\%) & 19.7 & 40.5 & $44 I .5$ & 391 (30\%) & 638 (49\%) & $223(17 \%)$ & 57 (4\%) \\
\hline Belgium & 102 & 82 (80\%) & 23.6 & 51.8 & 443.0 & 70 (69\%) & 27 (26\%) & $2(2 \%)$ & $3(3 \%)$ \\
\hline Denmark & 101 & 78 (77\%) & 18.9 & 40.3 & 409.3 & $33(33 \%)$ & $63(62 \%)$ & $4(4 \%)$ & I (I\%) \\
\hline France & 100 & 78 (78\%) & 19.9 & 51.2 & 453.4 & $44(44 \%)$ & 45 (45\%) & $3(3 \%)$ & $8(8 \%)$ \\
\hline Germany & 100 & $64(64 \%)$ & 18.8 & 46.9 & 520.6 & $57(57 \%)$ & $4 I(41 \%)$ & 0 & $2(2 \%)$ \\
\hline Ireland & 101 & 62 (6I\%) & 18.3 & 36.0 & 382.6 & $36(36 \%)$ & $58(57 \%)$ & 7 (7\%) & 0 \\
\hline Italy & 100 & $82(82 \%)$ & 24.6 & 34.9 & 390.6 & 59 (59\%) & $29(29 \%)$ & 7 (7\%) & $5(5 \%)$ \\
\hline The Netherlands & 100 & 77 (77\%) & 19.8 & 38.6 & 529.9 & $28(28 \%)$ & $64(64 \%)$ & $6(6 \%)$ & $2(2 \%)$ \\
\hline Norway & 100 & 72 (72\%) & 16.9 & 35.0 & 331.6 & $13(13 \%)$ & $65(65 \%)$ & $18(18 \%)$ & $4(4 \%)$ \\
\hline Poland & 100 & 61 (61\%) & 16.7 & 38.0 & 589.4 & $24(24 \%)$ & 7I (7I\%) & I (I\%) & $4(4 \%)$ \\
\hline Portugal & 100 & $60(60 \%)$ & 22.3 & 42.9 & 399.3 & $9(9 \%)$ & $30(30 \%)$ & $50(50 \%)$ & II (I I\%) \\
\hline Spain & 101 & $81(80 \%)$ & 21.1 & 37.6 & 575.2 & II (I I\%) & $32(32 \%)$ & $50(50 \%)$ & $8(8 \%)$ \\
\hline Sweden & 100 & 68 (68\%) & 18.3 & 35.0 & 242.3 & $2(2 \%)$ & $52(52 \%)$ & 42 (42\%) & $4(4 \%)$ \\
\hline UK & 104 & 84 (81\%) & 16.7 & 38.0 & 470.5 & $5(5 \%)$ & $6 \mathrm{I}(59 \%)$ & $33(32 \%)$ & $5(5 \%)$ \\
\hline
\end{tabular}

Abbreviations: MDT, multidisciplinary team; PCP, primary care physician. 
the minority $(\mathrm{n}=57)$ stating that they worked within a large multidisciplinary team (definition not given) compared with other practices $(77 \%$ vs $87 \%-90 \%)$, and in those from Portugal ( $81 \%$ vs $\geq 91 \%$ of respondents in the UK, Sweden, and Ireland). On average, the PCPs surveyed perceived CNMP to be a low priority within the healthcare system, despite the challenges it poses (Figure 1). Regardless of sex, length of experience, and practice size, $79 \%$ of PCPs stated that the management of CNMP should be higher on the government health agenda; this view was particularly prevalent in Italy, France, Poland, Spain, and Portugal (88\%-91\%) compared with the Netherlands and Denmark $(\leq 55 \%)$. Nearly three-quarters of respondents (74\%) stated that chronic pain should be considered a disease in its own right (ranging from $56 \%$ of those in Denmark to $94 \%$ of those in Italy), though $57 \%$ considered that chronic pain is more a symptom than a condition (ranging from $42 \%$ in Germany and $43 \%$ in Italy to $70 \%$ in the Netherlands and $71 \%$ in Sweden).

\section{Pain assessment}

Fewer than half (48\%) of the PCPs used pain assessment tools (Table 2); this was significantly lower among those practicing for $\geq 31$ years $(31 \%)$ compared with physicians in practice for $6-20$ years $(52 \%-60 \%)(P<0.05)$. Pain assessment tools were used by $70 \%$ of doctors stating that they worked in a large multidisciplinary team (not defined), compared with $43 \%-49 \%$ of practitioners in other practices $(P<0.05)$. Among respondents using assessment tools $(\mathrm{n}=628)$, the most commonly used were visual analogue scales (mentioned by 64\%) and numerical rating scales (51\%). Although the majority (83\%) of those using assessment tools recorded the results in the patients' notes, this corresponded to just $40 \%$ of all PCPs surveyed.

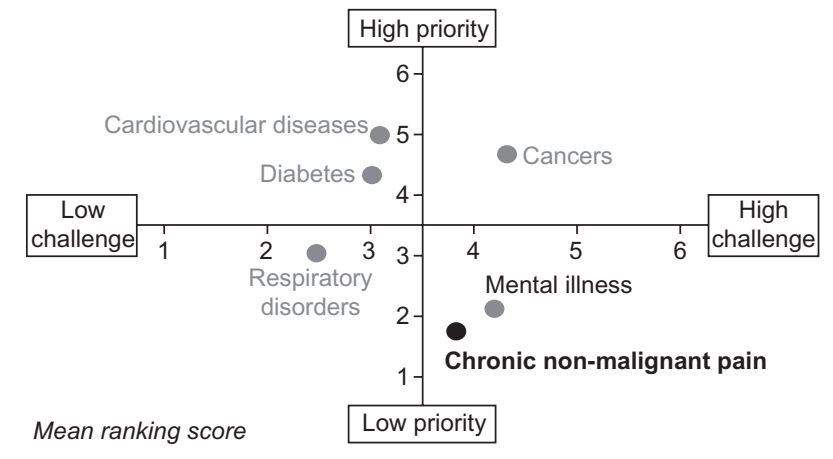

Figure I PCP perceptions of CNMP compared with other chronic conditions. Abbreviations: CNMP, chronic nonmalignant pain; PCP, primary care physician.
Table 2 Use of assessment tools

\begin{tabular}{llll}
\hline Country & N & $\begin{array}{l}\text { \% PCPs } \\
\text { using tools }\end{array}$ & $\begin{array}{l}\text { \% PCPs using tools but } \\
\text { not recording in notes }\end{array}$ \\
\hline Total & 1309 & 48 & 17 \\
Belgium & 102 & 42 & 23 \\
Denmark & 101 & 36 & 19 \\
France & 100 & 60 & 15 \\
Germany & 100 & 59 & 12 \\
Ireland & 101 & 37 & 8 \\
Italy & 100 & 39 & 28 \\
The Netherlands & 100 & 42 & 10 \\
Norway & 100 & 63 & 5 \\
Poland & 100 & 65 & 22 \\
Portugal & 100 & 48 & 38 \\
Spain & 101 & 52 & 11 \\
Sweden & 100 & 56 & 16 \\
UK & 104 & 26 & 22 \\
\hline
\end{tabular}

Abbreviation: PCP, primary care physician.

Among those not using assessment tools, the main reason given was lack of knowledge (26\%); this was a greater problem for those with many years of practice $(40 \%$ of those in practice for $\geq 31$ years vs $12 \%$ for $\leq 5$ years). Other reasons given included the view that tools were not useful $(18 \%)$, the lack of time $(16 \%)$, the preference "to just talk with the patient" (13\%), and the view that these were too impersonal $(12 \%)$.

Overall, $81 \%$ of PCPs surveyed believed that chronic pain and its impact on quality of life is underassessed in primary care. Fewer than half (49\%) of the PCPs reported having adequate time in their consultations with patients to discuss pain and its management, and only $64 \%$ felt they had adequate tools for the diagnosis and management of CNMP.

\section{Opioids}

Of the patients with CNMP seen by the respondents, $40 \%$ were managed without use of opioids, $40 \%$ used weak opioids only (commonly used for the management of mild to moderate pain), $11 \%$ used strong opioids only (commonly used for the management of moderately severe to severe pain), and $9 \%$ used both strong and weak opioids. PCPs were generally confident about prescribing opioids for cancer pain but less confident about opioid use in CNMP (Figure 2). Confidence was particularly low in Norway, Sweden, and Poland, with $46 \%$, $43 \%$, and $37 \%$, respectively, reporting a lack of confidence in the use of strong opioids for CNMP compared with $\leq 20 \%$ in the UK, the Netherlands, France, and Italy. Among the 304 PCPs who were very confident using strong opioids for CNMP, the most common reasons given were experience (mentioned by $34 \%$ ) and available treatments (33\% overall, 


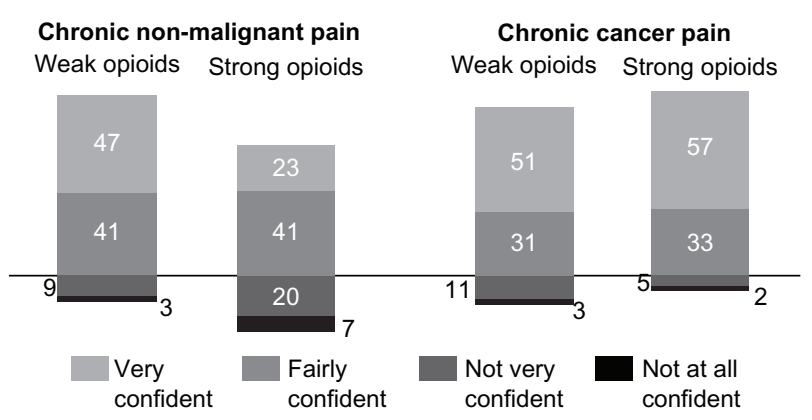

Figure 2 Proportion of PCPs $(\%[n=1305])$ reporting confidence in prescribing opioids for chronic pain.

Abbreviation: PCP, primary care physician.

with $70 \%$ in practitioners with $\leq 5$ years of experience vs $22 \%-40 \%$ in those practicing for longer). Among the 92 PCPs who were not confident at all about using strong opioids in CNMP, the main reasons given were concerns about addiction or abuse (35\%) and adverse events (22\%).

The majority of PCPs (86\%) reported that constipation was the side effect of strong opioids most commonly raised as an issue by patients (Figure 3); there was significantly lower reported concern about constipation in Portugal (56\%) than in all other countries $(P<0.05)$.

\section{Educational needs}

Overall, $84 \%$ of PCPs reported that their initial training in CNMP management was not comprehensive. More respondents from the UK, Belgium, Poland, and the Netherlands were dissatisfied with their initial training (88\%-91\%) than those in France, Germany, and Ireland (72\%-78\%). During the preceding year, $75 \%$ of respondents had received formal training and education on CNMP management, with a lower proportion in Sweden (42\%) than in all other countries and $\geq 92 \%$ in Italy, Spain, and Poland. This training was for an average of 10 hours and was significantly lower ( $\leq 5$ hours) in

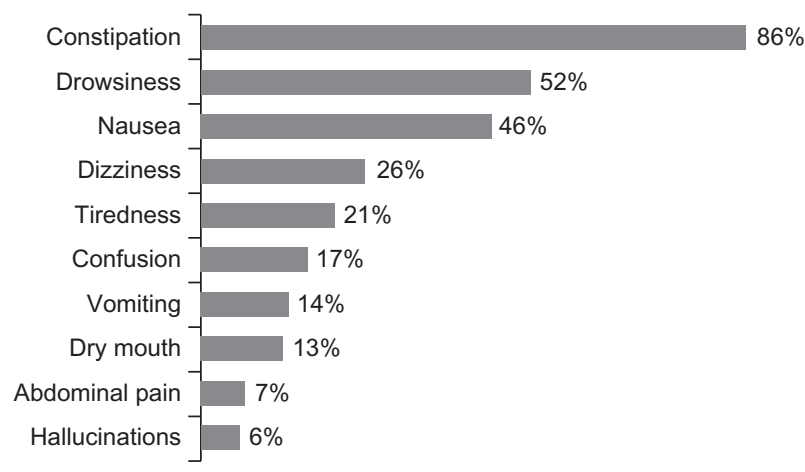

Figure 3 Side-effects of strong opioids reported by PCPs as most commonly raised by patients.

Abbreviation: PCP, primary care physician.
UK, France, Sweden, Belgium, the Netherlands, and Ireland compared with $\geq 20$ hours in Italy and Spain $(P<0.05)$. The main reason given by the 332 respondents who had not received such training during the last year was lack of time (mentioned by $70 \%$ ). Most PCPs (89\%) surveyed perceived a need for more education on CNMP management.

Guidelines for pain management appear to be used more commonly for cancer pain than for CNMP (Figure 4). There are no universal guidelines for the management of CNMP, though $72 \%$ of respondents reported that these were required. This view was significantly more prevalent in women ( $76 \%$ vs $70 \%$ in men) $(P<0.05)$, recently qualified doctors $(79 \%-83 \%$ of PCPs with $\leq 10$ years experience vs $63 \%-67 \%$ of PCPs with $\geq 26$ years experience), and those working with other PCPs and in multidisciplinary teams ( $73 \%-84 \%$ vs $62 \%$ of single practitioners). There were also considerable differences between countries, ranging from $96 \%$ and $91 \%$ in Spain and Poland, respectively, to $57 \%$ in France and Italy.

\section{Discussion}

This large survey showed that PCPs in Europe, like their counterparts in North America, find the primary care management of CNMP a considerable challenge. ${ }^{3,5,7,9}$ Fewer than half of the PCPs across Europe used pain assessment tools, and the majority of respondents recognized that chronic pain and its impact on quality of life are under-assessed in primary care. There was some lack of confidence in prescribing strong opioids for CNMP. Overall, 89\% of PCPs perceived a need for more education on chronic pain, and there was considerable demand for clinical guidelines focused on the management of CNMP.

The study has a number of limitations. Because of the online-survey format, respondents were self-selected, though

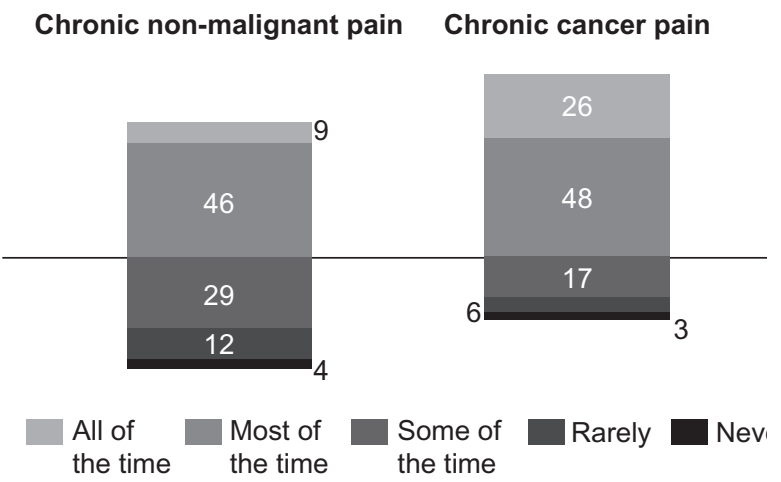

Figure 4 Proportion of PCPs (\% $[n=1305])$ reporting use of guidelines for chronic pain.

Abbreviation: PCP, primary care physician. 
representative of the PCP population within each country. Respondents were drawn from 13 countries, each with its own healthcare system, so there was considerable heterogeneity in terms of the size of primary care practices and the number of patients seen by each physician, although this approach ensured the results reflected the broad European situation. It should be noted that the overall findings of this survey were consistent with those of other approaches (eg, postal surveys, discussion groups) used in other surveys of PCPs. ${ }^{8,9,11}$ As with other surveys, time and size constraints of the study meant that related topics (eg, attitudes towards nonpharmacological management of pain) could not be considered.

The survey found a lack of clear guidelines for the assessment and management of CNMP (or lack of awareness of such guidelines). Although CNMP was seen by the majority of PCPs as a condition in its own right, guidelines on pain management may be fragmented - there are multiple guidelines for specific conditions (eg, headache, musculoskeletal conditions) that have chronic pain as a symptom. The numerous gaps in evidence may contribute to the lack of appropriate guidelines, and there is a need for further research in the management of CNMP. ${ }^{12} \mathrm{~A}$ recent review of the evidence available to guide the management of chronic pain in primary care, and other surveys of PCPs, also identified a lack of CNMP guidelines for the primary care setting. ${ }^{11,13}$ There appears to be an important potential role for professional organizations in developing and disseminating European guidelines for the management of CNMP in primary care.

Despite the recognized importance of formal evaluation to guide treatment and assess response, ${ }^{14}$ the survey found that over half the PCPs did not use tools to assess CNMP, primarily due to lack of knowledge, particularly amongst PCPs who have been in practice for many years. This situation could be addressed by improved education. There may also be a need for improved assessment tools, consistent with findings from PCPs in the USA. ${ }^{15}$ In another survey, PCPs reported a mean of 2.3 minutes spent on discussions about pain during their consultations with elderly patients and concluded that time constraints adversely affected pain management, ${ }^{16}$ suggesting that assessment tools should be quick and easy to use.

While short-term studies have established the clinical effectiveness of opioids for CNMP, evidence on long-term use remains limited. ${ }^{12}$ The survey found that $40 \%$ of the patients seen by the PCPs did not use any opioids for the management of CNMP, while one in five (20\%) were managed using strong opioids (presumably for moderately severe to severe pain). Although almost two-thirds of respondents (64\%) were fairly or very confident in the use of strong opioids for CNMP, more than a quarter of respondents $(27 \%)$ showed some lack of confidence. Similar findings have been reported in other studies, $, 3,15$ including one US study that found $71 \%$ of PCPs felt moderately or strongly confident of their ability to treat chronic pain.?

The pan-European survey reported here and others have found PCPs are concerned about the potential for opioid addiction or misuse. ${ }^{17,18} \mathrm{~A}$ study of PCPs in the USA found that although most respondents believed it lawful and appropriate to use opioids for cancer pain, fewer than half held this view for CNMP; ${ }^{9}$ that study and others found widespread concerns that PCPs using such treatment could become the subject of investigation. ${ }^{8,19,20}$ Such US experiences and concerns may influence European PCPs.

The survey suggested some concern among PCPs about the potential for side effects from opioids. In a survey of PCPs in Canada, $42 \%$ reported that patients using opioids for CNMP had experienced at least one adverse event during the preceding year. ${ }^{8}$ According to the present study, constipation is the side effect of strong opioids most commonly raised as an issue by patients, consistent with other studies showing the high frequency of opioid-related bowel dysfunction in patients receiving treatment for chronic pain. ${ }^{21-23}$ The OMPC may be able to address the need for education to improve patient selection for opioid treatment and subsequent monitoring, and to disseminate information about minimizing opioid-related bowel dysfunction.

The survey found dissatisfaction with education on CNMP management, consistent with the findings of other studies. Despite pain being a common reason for primary care consultation, ${ }^{18,24}$ education about pain represents less than $1 \%$ of university-based teaching for healthcare professionals. ${ }^{25}$ In a study of medical undergraduates, most held negative views about pain management, particularly regarding chronic pain; $;{ }^{24}$ medical students also experience considerable anxiety about encounters with patients suffering from chronic pain. ${ }^{26}$ Training on pain should address interviewing skills as well as knowledge of pain mechanisms. ${ }^{27}$

\section{Conclusion}

This large survey conducted in 13 European countries has shown that PCPs find CNMP a challenge to treat. Training in the use of assessment tools and the appropriate prescription of strong opioids, and the development of guidelines on primary care CNMP management would be welcomed by European PCPs. These findings should provide the basis 
for future initiatives by the OMPC and other organizations to support primary care management of chronic pain in Europe.

\section{Acknowledgments}

The findings are presented here on behalf of the OPENMinds Primary Care group: M Johnson, UK; B Collett, UK; JM Castro-Lopes, Portugal; F Corti, Italy; J Draiby, Sweden; F Hirszowski, France; K Kristiansen, Denmark; A Norman Hansen, Norway; U Schutter, Germany; V Simovich, Israel; JMP van Bommel, Netherlands; SF van Laer, Belgium.

\section{Disclosure}

The survey was conducted by Ipsos MORI and sponsored by an educational grant from Mundipharma International Limited. OPENMinds and OMPC are funded by educational grants from Mundipharma International Limited. MJ has received consultancy fees, honoraria, and travel expenses from Astellas, AstraZeneca, Grünenthal, Lilly, Mundipharma, NAPP, Nycomed, and Pfizer. BC has received consultancy fees, honoraria, and travel expenses from Astellas, Grünenthal, Lilly, Mundipharma, NAPP, and Pfizer. JMC-L has received consultancy fees, honoraria, or travel expenses from Astellas, Bene Farmacêutica, Grünenthal, Janssen, Mundipharma, and Pfizer. Diane Storey of Direct Publishing Solutions Limited prepared the first draft of the manuscript for the authors' review and provided editorial support funded by Mundipharma International Limited. The authors report no other conflicts of interest in this work.

\section{References}

1. Breivik H, Collett B, Ventafridda V, Cohen R, Gallacher D. Survey of chronic pain in Europe: prevalence, impact on daily life, and treatment. Eur J Pain. 2006;10(4):287-333.

2. Crombie IK. Epidemiologic studies of pain. Journal of the Pain Society. 1993;11:30-32.

3. Upshur CC, Luckmann RS, Savageau JA. Primary care provider concerns about management of chronic pain in community clinic populations. $J$ Gen Intern Med. 2006;21(6):652-655.

4. Von Korff M, Dworkin SF, Le Resche L. Graded chronic pain status: an epidemiologic evaluation. Pain. 1990;40(3):279-291.

5. Leverence RR, Williams RL, Potter M, et al; Prime Net Clinicians. Chronic non-cancer pain: a siren for primary care - a report from the PRImary Care MultiEthnic Network (PRIME Net). J Am Board Fam Med. 2011;24(5):551-561.

6. Sinatra R. Opioid analgesics in primary care: challenges and new advances in the management of noncancer pain. J Am Board Fam Med. 2006;19(2):165-177.

7. Dobscha SK, Corson K, Flores JA, Tansill EC, Gerrity MS. Veterans affairs primary care clinicians' attitudes toward chronic pain and correlates of opioid prescribing rates. Pain Med. 2008;9(5):564-571.

8. Wenghofer EF, Wilson L, Kahan M, et al. Survey of Ontario primary care physicians' experiences with opioid prescribing. Can Fam Physician. 2011;57(3):324-332.
9. Wolfert MZ, Gilson AM, Dahl JL, Cleary JF. Opioid analgesics for pain control: Wisconsin physicians' knowledge, beliefs, attitudes, and prescribing practices. Pain Med. 2010;11(3):425-434.

10. IASP Task Force on Taxonomy. Part III: Pain terms, a current list with definitions and notes on usage. In: Merskey H, Bogduk N, editors. Classification of Chronic Pain, 2nd ed. Seattle: IASP Press; 1994.

11. Clark LG, Upshur CC. Family medicine physicians' views of how to improve chronic pain management. J Am Board Fam Med. 2007;20(5):479-482.

12. Chou R, Ballantyne JC, Fanciullo GJ, Fine PG, Miaskowski C. Research gaps on use of opioids for chronic noncancer pain: findings from a review of the evidence for an American Pain Society and American Academy of Pain Medicine clinical practice guideline. J Pain. 2009; 10(2):147-159.

13. Smith BH, Torrance N. Management of chronic pain in primary care. Curr Opin Support Palliat Care. 2011;5(2):137-142.

14. Scholz J, Mannion RJ, Hord DE, et al. A novel tool for the assessment of pain: validation in low back pain. PLoS Med. 2009;6(4): e1000047.

15. Spitz A, Moore AA, Papaleontiou M, Granieri E, Turner BJ, Reid MC. Primary care providers' perspective on prescribing opioids to older adults with chronic non-cancer pain: a qualitative study. BMC Geriatr. 2011;11:35.

16. Tai-Seale M, Bolin J, Bao X, Street R. Management of chronic pain among older patients: inside primary care in the US. Eur J Pain. 2011;15(10):1087.

17. Gooberman-Hill R, Heathcote C, Reid CM, et al. Professional experience guides opioid prescribing for chronic joint pain in primary care. Fam Pract. 2011;28(1):102-109.

18. Lewis ET, Trafton JA. Opioid use in primary care: asking the right questions. Curr Pain Headache Rep. 2011;15(2):137-143.

19. Green CR, Wheeler JR, Marchant B, LaPorte F, Guerrero E. Analysis of the physician variable in pain management. Pain Med. 2001;2(4): 317-327.

20. Nwokeji ED, Rascati KL, Brown CM, Eisenberg A. Influences of attitudes on family physicians' willingness to prescribe long-acting opioid analgesics for patients with chronic nonmalignant pain. Clin Ther. 2007;29 Suppl:2589-2602.

21. Bell TJ, Panchal SJ, Miaskowski C, Bolge SC, Milanova T, Williamson R. The prevalence, severity, and impact of opioid-induced bowel dysfunction: results of a US and European Patient Survey (PROBE 1). Pain Med. 2009;10(1):35-42.

22. Moore RA, McQuay HJ. Prevalence of opioid adverse events in chronic non-malignant pain: systematic review of randomised trials of oral opioids. Arthritis Res Ther. 2005;7(5):R1046-R1051.

23. Rosti G, Gatti A, Costantini A, Sabato AF, Zucco F. Opioid-related bowel dysfunction: prevalence and identification of predictive factors in a large sample of Italian patients on chronic treatment. Eur Rev Med Pharmacol Sci. 2010;14(12):1045-1050.

24. Corrigan C, Desnick L, Marshall S, Bentov N, Rosenblatt RA. What can we learn from first-year medical students' perceptions of pain in the primary care setting? Pain Med. 2011;12(8):1216-1222.

25. Briggs E, Whittaker M, Carr M; British Pain Society Pain Education Special Interest Group. Survey of Undergraduate Pain Curricula for Healthcare Professionals in the United Kingdom: A Short Report. London: British Pain Society; 2009. Available from: http://www.britishpainsociety.org/members_sig_edu_short_report_survey.pdf. Accessed February 2, 2013.

26. Niemi-Murola L, Nieminen JT, Kalso E, Pöyhiä R. Medical undergraduate students' beliefs and attitudes toward pain: how do they mature? Eur J Pain. 2007;11(6):700-706.

27. Leila NM, Pirkko H, Eeva P, Eija K, Reino P. Training medical students to manage a chronic pain patient: both knowledge and communication skills are needed. Eur J Pain. 2006;10(2):167-170. 


\section{Supplementary material OPENMinds Primary Care questionnaire}

\section{Section I:Assessment}

Q1. How many patients do you see in an average month?

Q2. Out of these patients, how many would suffer from non-malignant chronic pain in an average month?

Q3. Out of these non-malignant chronic pain patients, how many on average would be new patients and how many would be follow-up patients?

Q4. When managing your patients with chronic nonmalignant pain do you use any assessment scales/ tools?

Q5. As standard practice which assessment scales/tools do you use to assess pain in patients with non-malignant chronic pain?

Q6. Why do you not use any assessment scales/tools to assess pain in patients with non-malignant chronic pain?

Q7. Do you record the results of the assessment scales/ tools in the patients' medical records?

Q8. Do you have access to a pain clinic to refer nonmalignant chronic pain patients to?

Q9. How many patients do you refer to a pain clinic in an average year?

Q10. What are your three most common reasons for referring these patients to a pain clinic? Please rank these three reasons in terms of how common they are.

Q11. Which of the following best describes your approach for following up with patients that you initiate on pain medication for the management of non-malignant chronic pain?

I ask the patient to return or seek advice if they do not respond to the treatment

I schedule a routine follow-up irrespective of the patient's response to the therapy

I do not schedule a follow-up

Other - please specify

Q12. Which of the following best describes your approach for following up with patients that are receiving ongoing pain medication for the management of nonmalignant chronic pain?

I ask the patient to return or seek advice if they do not respond to the treatment

I schedule a routine follow-up irrespective of the patient's response to the therapy
I do not schedule a follow-up

Other - please specify

\section{Section 2: Education and guidelines}

Q13. To what extent do you refer to guidelines for the management of patients with non-malignant chronic pain and for the management of patients with malignant pain?

Q14. Which guidelines for the management of patients with non-malignant chronic pain do you refer to?

Q15. To what extent do you think specific guidelines are required for the management of non-malignant chronic pain and for the management of malignant pain?

Q16. Please now think about the training you received during your medical course (pre-graduation). How comprehensive, if at all, was the training you received specific to the management of non-malignant chronic pain?

Q17. In the past year, how many hours have you spent on formal training (including accredited training) and education specific to non-malignant chronic pain?

Q18. What would be your preferred formats of learning for non-malignant chronic pain today?

Q19. To what extent do you agree or disagree that more education is required in the area of non-malignant chronic pain management for primary care physicians?

Q20. What has prevented you from undertaking additional training or education in the area of non-malignant chronic pain management?

Q21. What would motivate you to undertake additional training or education in the area of non-malignant chronic pain management?

\section{Section 3: Policy}

Q22. To what extent do you agree or disagree with each of the following statements?

Non-malignant chronic pain is one of the most challenging conditions to treat

Patients with non-malignant chronic pain are more challenging to manage than the typical patient

I have adequate tools to diagnose and manage patients with non-malignant chronic pain

I have adequate time in my consultations to discuss non-malignant chronic pain with patients

The management of non-malignant chronic pain should be higher on the government's health agenda 
Chronic pain should be considered as a disease in its own right

Chronic pain is more of a symptom than a condition Chronic pain and its impact on quality of life tends to be under-assessed in primary care

Apart from the duration of pain, there are no differences between chronic pain and acute pain

Q23. Which one of the following statements do you most agree with?

Chronic pain is definitely a medical symptom

Chronic pain is more a medical symptom than a psychological symptom

Chronic pain is a medical and psychological symptom

Chronic pain is more a psychological symptom than a medical symptom

Chronic pain is definitely a psychological symptom

Q24. In your opinion, how much of a challenge is posed by each of the following in terms of treatment?

Non-malignant chronic pain

Respiratory disorders

Cardiovascular diseases

Mental illness

Cancers

Diabetes

Q25. In your opinion, how much of a priority are each of the following conditions within the healthcare system?

Non-malignant chronic pain

Respiratory disorders

Cardiovascular diseases

Mental illness

Cancers

Diabetes

\section{Section 4: Opioid usage}

Q26. Are special prescription forms needed to prescribe weak and/or strong opioids?

Q27. How easy or difficult is it for you to write weak and/or strong opioids prescriptions using these forms?

Q28. Please rank opioids in terms of their strength/ potency.

Q29. How many of the patients with non-malignant chronic pain that you see in a typical month are managed with opioids?
Q30. How confident, if at all, are you in prescribing opioids for non-malignant chronic pain patients and for malignant pain patients?

Q31. Why do you say that you have this confidence in prescribing strong opioids for non-malignant chronic pain patients?

Q32. Which of the following best describes your approach for following up with patients that you initiate on strong opioids for management of non-malignant chronic pain?

I ask the patient to return or seek advice if they do not respond to the treatment

I schedule a routine follow-up irrespective of the patient's response to the therapy

I do not schedule a follow-up

I do not initiate strong opioids

Other-please specify

Q33. Which of the following are your key reasons for not initiating the prescription of strong opioids to patients for the management of non-malignant chronic pain?

Patients' pain is not severe enough

Difficulty identifying appropriate patients

Concerns over dependency/addiction

Price

Lack of reimbursement

Lack of guidelines

It is not available by law

Side effects

Patients don't want to be treated with strong opioids Lack of confidence/understanding of strong opioids Controlled drug status

Other - please specify

None of the above

Q34. To what extent, if at all, does each of the following influence your decision to prescribe strong opioids to a patient?

Patient's ability to drive while taking strong opioids Patient's ability to work Patient's ability to perform household tasks Patient's ability to look after children and/or family I do not prescribe strong opioids

Q35. How frequently, on average, would you ask these patients on strong opioids to return for a routine follow-up after initiating them on the treatment? 
Q36. What are the 3 most important factors you take into account when initiating a patient on strong opioid therapy for management of non-malignant chronic pain? Please rank these three factors in terms of how important they are.

Q37. How important, if at all, are the following when considering initiating treatment of strong opioid therapy for management of non-malignant chronic pain?

Reduction in pain (efficacy)

Improvement in functioning

Side effects

Quality of life

Q38. Which one of the following would you say is the most important factor when considering initiating treatment of a patient on strong opioid therapy for management of non-malignant chronic pain, above all others?

Reduction in pain (efficacy)

Improvement in functioning

Side effects

Quality of life
Q39. Which three side effects do patients prescribed strong opioids most commonly raise as an issue?

Q40. Please rank these three side effects you have selected, in terms of how frequently they are raised as an issue by patients.

Q41. And finally, in your opinion please rank these three side effects you have selected, in terms of how difficult they are to treat.

Q42. In light of the topics covered today, what else would you like to add?
Journal of Pain Research

\section{Publish your work in this journal}

The Journal of Pain Research is an international, peer-reviewed, open access, online journal that welcomes laboratory and clinical findings in the fields of pain research and the prevention and managemen of pain. Original research, reviews, symposium reports, hypothesis formation and commentaries are all considered for publication.

\section{Dovepress}

The manuscript management system is completely online and includes a very quick and fair peer-review system, which is all easy to use. Visit http://www.dovepress.com/testimonials.php to read real quotes from published authors. 